\title{
ESTRATÉGIAS DE LEITURA DA TRADIÇÃO LITERÁRIA BRASILEIRA NA CRÍTICA DE MACHADO DE ASSIS
}

\author{
Andréa Sirihal Werkema \\ Universidade do Estado do Rio de Janeiro \\ Rio de Janeiro (RJ), Brasil
}

\begin{abstract}
Resumo: Neste artigo, são discutidas as estratégias utilizadas por Machado de Assis, em seu célebre ensaio "Instinto de nacionalidade" (1873), para não apenas inserir a sua própria produção literária no quadro da literatura brasileira de então, mas também para lançar um olhar sobre as futuras possibilidades, a partir daquele momento, de produção de uma literatura não pautada pelo crivo do nacionalismo literário no Brasil. Ou seja, o ensaio de Machado lançaria, para nós, leitores a posteriori, uma luz especial sobre a futura obra ficcional do autor, já que ele proporia um princípio de indeterminação do índice diferenciador dos textos da literatura brasileira, índice até então associado aos traços brasileiristas aí encontrados.
\end{abstract}

Palavras-chave: crítica literária; nacionalismo literário; tradição.

\section{Reading strategies of the Brazilian literary tradition in critical texts by Machado de Assis}

\begin{abstract}
This article discusses the strategies used by Machado de Assis in his famous essay "Instinto de nacionalidade" (1873), not only to insert his literary production in the context of Brazilian literature of the time, but also to speculate about the future of a literature not based on Brazilian literary nationalism, or dependent on it. In other words: Machado's essay provides us, his future readers, with a special light over his own fictional work of years to come, since it proposes a principle of indetermination in order to individualise Brazilian literature, a principle that had depended, until that point, on the specifically Brazilian traits found in literary texts.
\end{abstract}

Keywords: literary criticism; literary nationalism; tradition. 
Discutindo o significado do ensaio "Instinto de nacionalidade", ${ }^{1}$ de Machado de Assis, em relação à questão da nacionalidade da literatura brasileira, propõe Abel Barros Baptista uma primeira leitura do problema:

Trata-se de estudá-lo, não na perspectiva de um episódio de origem, projetando luz sobre toda a sua obra, como se fosse um projeto alternativo, mas como episódio em que Machado procura delimitar um estatuto para a sua assinatura resistindo à lei nacional. É o momento em que a reflexão machadiana sobre a questão da nacionalidade literária desarticula a retórica solidária do projeto nacional legado pelo romantismo, quebrando o laço entre a realidade brasileira entendida como realidade fundadora e a literatura, demarcando-se, em consequência, não apenas do projeto nacional, mas de todo o projeto em literatura: o episódio brasileiro do nome de Machado é o momento em que, para se erguer acima do quadro literário nacional, Machado lança a indeterminação sobre o esforço de construção de uma literatura nacional. $^{2}$

Em termos muito rápidos, eu gostaria de apontar aí a questão central do ensaio de Baptista: o modo como Machado inscreve seu nome na história da literatura brasileira, contra qualquer prescrição nacionalista, não opera pela negação de tais prescrições nacionalistas. Opera antes pela sugestão de uma outra força na condução dos destinos literários, isto é, pela literatura em si. No entanto, se "Instinto de nacionalidade" não é de fato um projeto alternativo, ponto de origem da reflexão de Machado sobre os rumos da literatura brasileira e de sua própria obra literária aí inserida, não custa lembrar que tais preocupações já frequentavam a crítica machadiana desde a década de 1860. É preciso ressaltar, nas resenhas escritas por Machado de Assis sobre obras de escritores românticos, como José de Alencar ou Álvares de Azevedo, a sua preocupação em encontrar ali um fio crítico, de reflexão não apenas sobre as questões nacionais em literatura, mas sobre questões inerentes ao fazer literário. Voltarei a isso mais adiante. Gostaria apenas de deixar aqui anotado o fato de que essa ampla discussão sobre os rumos de uma literatura, como desenvolvida por Machado,

\footnotetext{
${ }^{1}$ ASSIS, Machado de. Notícia da atual literatura brasileira - Instinto de nacionalidade. In: Obra completa. v. 3. Rio de Janeiro: Nova Aguilar, 1997. p. 801-809. Publicado originalmente em Novo Mundo, no dia 24 de março de 1873.

2 BAPTISTA, Abel Barros. A formação do nome: duas interrogações sobre Machado de Assis. Campinas: Editora da Unicamp, 2003. p. 42.
} 
tem entre seus endereços certos uma óbvia inserção de si mesmo no âmbito dessa mesma literatura, o que é também apontado por Abel Barros Baptista. E para se inserir no continuum literário brasileiro, se é que podemos observar tal fenômeno já em fins do século XIX, Machado de Assis prefere antes lançar dúvidas, desestabilizar certezas e provocar desconfianças em relação a um cânone nacionalista que ameaçava homogeneizar uma compreensão do que fosse literatura brasileira.

Daí a dificuldade de se definir o que vem a ser um "instinto de nacionalidade", já que o termo "instinto", com a sua carga forte de indeterminação, parece caminhar na contramão de um projeto ou programa literário. O instinto seria anterior à reflexão crítica, está claro, mas pode estar muito próximo, anotemos, do momento criativo, do insight, ${ }^{3}$ que é posteriormente corrigido, refreado, inibido pela reflexão sistemática.

Pois é esse, me parece, o próprio movimento de Machado de Assis em seu ensaio "Instinto de nacionalidade" e em outros momentos de sua crítica literária: observar os vislumbres e necessidades envolvidos na criação de uma literatura nacional e corrigi-los no ensaio crítico ou na resenha, antes que fossem incorporados de vez às formas mais complexas da narrativa machadiana. Dando um passo atrás, gostaria de revisitar, em primeiro lugar, a resenha sobre Iracema, de José de Alencar, publicada em $1866 .^{4}$

Machado de Assis começa por introduzir a questão do indianismo na literatura brasileira, seus representantes e adversários. Nota-se que Machado procura discriminar, entre os vários autores que produziram obras indianistas, os criadores dos imitadores - e isso se faz pela leitura individualizada de cada autor, e não pela consideração do indianismo enquanto fenômeno da literatura brasileira ("Nem nos parece que se deva chamar escola ao movimento que atraiu as musas nacionais para o tesouro das tradições indígenas"). ${ }^{5}$ Com isso, Machado procura afastar também o maior medo dos adversários do indianismo: a sua transformação em modo exclusivo de fazer literatura brasileira.

\footnotetext{
${ }^{3}$ Em diferentes dicionários, "insight" aparece definido como: "clareza súbita na mente, no intelecto de um indivíduo"; "iluminação, estalo, luz, intuição, revelação, compreensão intuitiva". Conferir: <http://houaiss.uol.com.br/busca.jhtm?verbete=insight\&stype=k>. Acesso em 11 mar. 2012. Gostaria ainda de acrescentar os possíveis significados do termo "vislumbre".
}

${ }^{4}$ ASSIS, Machado de. José de Alencar: Iracema. In: Obra completa. v. 3, cit., p. 848-852. Publicado no Diário do Rio de Janeiro, no dia 23 de janeiro de 1866.

${ }^{5}$ ASSIS, Machado de. Obra completa. v. 3, cit., p. 848. 
Machado não tem dúvidas: para o verdadeiro criador, este era apenas mais um "dos modos de exercer a poesia nacional". ${ }^{6} \mathrm{O}$ indianismo, aos olhos de Machado de Assis, constitui-se em patrimônio da literatura brasileira, mas apenas na medida em que foi trabalhado como dispositivo estético por nossos grandes autores; deve-se ignorar as limitações dos "maus rimadores", que ameaçam transformar o motivo indígena em massa amorfa, e obrigatória, de clichês e adereços exóticos. Uma vez que se distinguem os bons dos maus poetas, e que se afasta a ameaça de uma literatura brasileira eternamente indianista, passa a ser possível analisar o romance de José de Alencar pela via do critério estético, à revelia de possíveis critérios extraliterários. Iracema é, segundo Machado de Assis, "um poema em prosa", fruto de trabalho minucioso de Alencar:

\begin{abstract}
Estudando profundamente a língua e os costumes dos selvagens, obrigou-se o autor a entrar mais ao fundo da poesia americana; entendia ele, e entendia bem, que a poesia americana não estava completamente achada; que era preciso prevenir-se contra um anacronismo moral, que consiste em dar ideias modernas e civilizadas aos filhos incultos da floresta. [...] a verdade é que relemos atentamente o livro do Sr. José de Alencar, e o efeito que ele nos causa é exatamente o mesmo a que o autor entende que se deve destinar ao poeta americano; tudo ali nos parece primitivo; a ingenuidade dos sentimentos, o pitoresco da linguagem, tudo, até a parte narrativa do livro, que nem parece obra de um poeta moderno, mas uma história de bardo indígena [...]. A conclusão a tirar daqui é que o autor houve-se nisto com uma ciência e uma consciência, para os quais todos os nossos louvores são poucos. ${ }^{7}$
\end{abstract}

Através da apreciação extremamente positiva do livro de Alencar, podemos acompanhar, no trecho citado, o percurso da leitura crítica - Machado parte das teses alencarinas expostas no posfácio "Carta ao Dr. Jaguaribe", 8 que acompanha Iracema, coloca-as à prova na releitura minuciosa do romance e chega à conclusão de que as experiências formais que lhe constituem o cerne foram bem-sucedidas na medida em que, primeiro, alcançam um efeito no leitor análogo ao desejo autoral; segundo, expõem

\footnotetext{
${ }^{6}$ Ibidem.

${ }^{7}$ Idem, p. 849.

${ }^{8}$ ALENCAR, José de. Carta ao Dr. Jaguaribe. In: 1964. p. 1122-1125.
} Ficção completa. v. 2. Rio de Janeiro: Aguilar, 
na matéria romanesca o trajeto reflexivo do autor, "ciência e consciência", motivos pelos quais os louvores do crítico são justos, na medida.

Se Iracema é um momento complexo em nosso Romantismo, alegra perceber que o romance teve um leitor à sua altura logo no primeiro momento; o que é aqui mais interessante, no entanto, é constatar que o uso sofisticado do arsenal indianista/brasileirista não encobriu o tour de force formal, produto da reflexão continuada sobre os meios da escrita. Parece-me bastante claro que uma virada crítica na avaliação da literatura brasileira, como a proposta por Machado de Assis em "Instinto de nacionalidade", tem suas raízes na leitura criteriosa de projetos literários consequentes como o de José de Alencar. Não é a utilização do motivo indígena que faz de Iracema o grande poema nacional ("modelo para o cultivo da poesia americana"), ${ }^{9}$ mas a meditação, o sentimento e a consciência que ressaltam em sua leitura ("para ele enviamos os leitores estudiosos"). ${ }^{10}$ Para falar ainda com Abel Barros Baptista (ou já um pouco distante dele, pois o crítico ignora, talvez por razões instrumentais, os ensaios machadianos da década de 1860), eu poderia deslocar de "Instinto de nacionalidade" para a resenha sobre Iracema um movimento claro de recusa: "Aí reside o cerne da recusa machadiana: não aceita que, em nome da nacionalidade, se limitem os 'cabedais' da literatura brasileira, ou, dito de outra forma, não aceita que a literatura brasileira tenha que ser pobre para conquistar o caráter nacional que procura". ${ }^{11}$

Ora, riqueza e pobreza, em termos de tradição literária, podem e devem ser traduzidas no contato (ou na ausência de contato) com outras literaturas, no aproveitamento de outros modelos formais e no diálogo entre os gêneros literários. Essa vivência dos textos alheios, como sabemos, só se torna verdadeiramente produtiva no momento em que o autor-leitor consegue transformá-la em algo próprio. Riqueza literária é, sob esse ponto de vista, um arsenal textual à disposição dos autores de determinada literatura nacional - e é, ao mesmo tempo, a capacidade que cada um desses autores tem de trabalhar criativamente dentro de uma tradição.

\footnotetext{
${ }^{9}$ ASSIS, Machado de. Obra completa. v. 3, cit., p. 852.

${ }^{10}$ Ibidem.

${ }^{11}$ BAPTISTA, Abel Barros. A formação do nome: duas interrogações sobre Machado de Assis, cit., p. 79 e 80 .
} 
Na resenha crítica feita sobre Lira dos vinte anos (1853), de Álvares de Azevedo, ${ }^{12}$ essa relação com a literatura europeia aparece problematizada por outro ângulo. Quem lê o texto crítico de Machado de Assis sobre Álvares de Azevedo forma de imediato a ideia de um poeta ainda em desenvolvimento, incompleto, com a carreira que se anunciava brilhante abreviada pela morte. Aquilo que o crítico condena em Azevedo assume certa relevância ao pensarmos no futuro escritor Machado de Assis - o excesso de leituras, a erudição descontrolada assenhoreando-se do texto: "Era frequentemente difuso e confuso; faltava-lhe precisão e concisão. Tinha os defeitos próprios das estreias, mesmo brilhantes como eram as dele. Procurava a abundância e caía no excesso. A ideia lutava-lhe com a pena, e a erudição dominava a reflexão." ${ }^{13}$ Um autor-leitor incomodado pelo excesso de leituras de outro autor-leitor. A formação de uma "individualidade poética" azevediana, nas palavras de Machado, necessitaria de mais tempo, mais reflexão, mais trabalho com a utilização de vozes alheias no próprio texto.

A reticência de Machado de Assis em relação à obra de Álvares de Azevedo parece sugerir um reconhecimento. Machado veria ali, em forma ainda incipiente, uma maneira possível de trabalhar as leituras na confecção de uma obra literária - riqueza. Tal questão assume ares sérios no contexto da literatura brasileira oitocentista, ameaçada pela tenuidade e pela pobreza quantitativa e qualitativa. Cobrar do mais romântico de nossos autores originalidade e individualidade não deixa de ser sintomático: Machado exige de um talento que ele previa superior uma definição mais clara de projeto literário, no quadro do Romantismo brasileiro (por isso seu elogio ao humour, como contribuição nova de Azevedo à literatura brasileira). Poderíamos pensar em um caso de reconhecimento de precursor ou de formação de uma linhagem crítica de trabalho criativo com as leituras feitas pelo autor-leitor. No entanto, para organizar e sistematizar na obra literária a riqueza advinda do contato com a literatura universal, torna-se fundamental contrabalançá-la com algo que poderíamos chamar - eis aqui - de "instinto de nacionalidade".

\footnotetext{
${ }^{12}$ ASSIS, Machado de. Álvares de Azevedo: Lira dos vinte anos. In: Obra completa. v. 3. Rio de Janeiro: Nova Aguilar, 1997. p. 892-894. Publicado no Diário do Rio de Janeiro, no dia 26 de junho de 1866.

${ }^{13}$ Idem, p. 894.
} 
Se o instinto precede a reflexão crítica, mas também a inicia e fornece a ela matéria para sistematização, temos aqui uma situação interessante: o "instinto de nacionalidade", que é busca por uma forma própria para a literatura brasileira, serviria como modo de bloquear ou filtrar o excesso de referências literárias estrangeiras e tornaria efetiva, no âmbito da literatura brasileira, a "dialética do local e do universal", para usar a expressão de Roberto Schwarz, ${ }^{14}$ que aponta em Machado de Assis (na esteira de Antonio Candido) o seu "aproveitamento crítico da literatura brasileira anterior, o que paradoxalmente o levava a dispensar os apoios do pitoresco e do exotismo, e lhe permitia integrar sem servilismo os numerosos modelos estrangeiros de que se valia". ${ }^{15}$ Poderíamos vislumbrar, no uso do termo "instinto de nacionalidade", uma dupla função: é um modo de descolar a literatura brasileira das certezas de um credo nacionalista/indianista/nativista lançando sobre ela a indeterminação de um impulso aparentemente cego; é também, e ao mesmo tempo, uma forma de organizar a literatura brasileira em suas relações com a literatura universal e com a produção local, mesmo em sua irregularidade. Só dessa maneira podemos imaginar a fundação de uma tradição literária entre nós, como entrevista naquele momento por Machado de Assis:

Quem examina a atual literatura brasileira reconhece-lhe logo, como primeiro traço, certo instinto de nacionalidade. Poesia, romance, todas as formas do pensamento buscam vestir-se com as cores do país, e não há negar que semelhante preocupação é sintoma de vitalidade e abono de futuro. As tradições de Gonçalves Dias, Porto Alegre e Magalhães são assim continuadas pela geração já feita e pela que ainda agora madruga, como aqueles continuaram as de José Basílio da Gama e Santa Rita Durão. ${ }^{16}$

Um continuum no qual se inserir é o que parece ainda preocupar Machado de Assis, por fim, em seu ensaio de 1879, "A nova geração", no qual o crítico se arrisca a julgar a poesia de seus contemporâneos. O ensaio se abre justamente com uma discussão sobre a relação conflituosa entre estilos de época que se sucedem no tempo:

\footnotetext{
${ }^{14}$ SCHWARZ, Roberto. Duas notas sobre Machado de Assis. In: Companhia das Letras, 2006. p. 168.

${ }^{15}$ Ibidem.

${ }^{16}$ ASSIS, Machado de. Obra completa. v. 3, cit., p. 801.
} 


\begin{abstract}
A nova geração chasqueia às vezes do Romantismo. Não se pode exigir da extrema juventude a exata ponderação das coisas; não há impor a reflexão ao entusiasmo. De outra sorte, essa geração teria advertido que a extinção de um grande movimento literário não importa a condenação formal e absoluta de tudo o que ele afirmou; alguma coisa entra e fica no pecúlio do espírito humano. Mais do que ninguém, estava ela obrigada a não ver no Romantismo um simples interregno, um brilhante pesadelo, um efeito sem causa, mas alguma coisa mais que, se não deu tudo o que prometia, deixa quanto basta para legitimá-lo. Morre porque é mortal. ${ }^{17}$
\end{abstract}

Essa passagem é lida por Abel Barros Baptista com especial atenção ao "pecúlio do espírito humano". Está claro que se discute aqui uma questão relativa à formação de uma tradição - riqueza literária -, não apenas em termos de literatura brasileira, mas como "atitude perante um movimento literário do passado assumida por um movimento literário do presente, independentemente de qualquer contexto nacional ou mesmo histórico." ${ }^{18}$ Interessa a mim observar, além disso, a necessidade aí descrita (camuflada pela condescendência para com a juventude) de refrear o entusiasmo através da reflexão e da ponderação. Tal movimento crítico, do instinto à reflexão, atualiza-se aqui na relação conturbada entre novos poetas e o passado poético próximo, execrado em sua totalidade por aqueles que julgam tê-lo ultrapassado. Machado levanta a bandeira do aprendizado e do "pecúlio": mas esses não se formam apenas pela acumulação linear, e sim pela escolha, explícita na passagem citada, daquilo que de uma geração poética anterior interessa a uma nova geração. Dessa maneira, com um pedido claro pela reflexão crítica acerca do passado literário próximo, com vistas ao futuro da literatura brasileira, Machado acaba por se excluir da "nova geração".

Distanciar-se do Romantismo através da filtragem de suas conquistas perenes é algo que parece orientar a produção do primeiro Machado de Assis prosador (faço aqui um desvio para evitar a poesia de Machado, já que me parece que sua produção de crítica literária tem continuidade em sua narrativa, e não exatamente em sua poesia). Para além das considerações nacionalistas, está claro que o Romantismo fora responsável pela criação de uma primeira massa textual (e crítica) considerável na

\footnotetext{
${ }^{17}$ ASSIS, Machado de. Obra completa. v. 3, cit., p. 810.

${ }^{18}$ BAPTISTA, Abel Barros. A formação do nome: duas interrogações sobre Machado de Assis, cit., p. 86.
} 
literatura brasileira: "deixa quanto basta para legitimá-lo". ${ }^{19}$ Machado parece enxergar, na inserção em uma continuidade crítica, a possibilidade de reivindicar, para a literatura brasileira, a preocupação exclusiva com questões propriamente literárias. Porque, uma vez admitida a existência de uma literatura entre nós, com o mínimo de consistência (o que atestam os ensaios críticos de Machado sobre autores de nossa literatura), pode-se começar a ignorar as discussões extraliterárias que empanaram a visão romântica brasileira. Voltamos então ao ensaio "Instinto de nacionalidade" e suas metáforas ambíguas: o "instinto de nacionalidade" em si e o "sentimento íntimo":

Não há dúvida que uma literatura, sobretudo uma literatura nascente, deve principalmente alimentar-se dos assuntos que lhe oferece a sua região; mas não estabeleçamos doutrinas tão absolutas que a empobreçam. O que se deve exigir do escritor antes de tudo, é certo sentimento íntimo, que o torne homem do seu tempo e do seu país, ainda quando trate de assuntos remotos no tempo e no espaço. ${ }^{20}$

Sim, o "sentimento íntimo" opõe-se à ostentação da "cor local"; por outro lado, traduz-se enquanto uma ligação profunda, de procedência interior, com a produção literária local, "seu tempo e seu país". Mas o "sentimento íntimo", da mesma maneira que o "instinto de nacionalidade", acaba por encontrar sua melhor tradução no sentido de ser uma busca, um processo, do qual faz parte a visita ao pitoresco enquanto "ponto de passagem - sublinhadamente fortuito - para esferas mais significativas". ${ }^{21}$

Eu tenderia a ver essa passagem para esferas mais significativas como uma preocupação em reconduzir, ou mesmo conduzir, as discussões sobre a literatura brasileira ao âmbito das discussões sobre a literatura em si. Como uma forma de atestar a maioridade, enfim, de nossa literatura nacional, exatamente pela afirmação de sua universalidade. Como uma reivindicação pela riqueza da literatura brasileira, "pecúlio" a se constituir na dialética entre o elemento local e o manancial da literatura ocidental. Portanto, o "sentimento íntimo" a ser exigido de um autor é mais um deslocamento da questão da nacionalidade em literatura, e não sua negação, assim como o "instinto de

\footnotetext{
${ }^{19}$ ASSIS, Machado de. Obra completa. v. 3, cit., p. 810.

${ }^{20}$ Idem, p. 804.

${ }^{21}$ SCHWARZ, Roberto. Duas notas sobre Machado de Assis, cit., p. 167.
} 
nacionalidade". E é também uma das formas da complexa autoinserção de Machado de Assis na literatura de sua época e de seu país:

[...] a posição de Machado será sempre incompatível com qualquer projeto, programa ou intenção nacionalista. A relação do escritor com o projeto nacional é profundamente alterada: Machado não lhe reconhece legitimidade para determinar o sentido da atividade literária, para excluir, decidir, escolher, distinguir o próprio do impróprio, o que, tendo presente a sua obra romanesca futura, aparece com indiscutível relevo. O que nestas páginas se decide é já a posição de Machado na literatura brasileira enquanto romancista. ${ }^{22}$

$\mathrm{Ou}$

Numa palavra, se o "sentimento íntimo" não é verdadeira proposta alternativa na questão nacional, é garantia individual fornecida pelo próprio Machado a respeito de si próprio; se quiserem julgá-lo segundo o critério da nacionalidade, se quiserem saber onde está a "brasilidade" das suas obras, procurem-lhe o sentimento íntimo. ${ }^{23}$

"Sentimento íntimo" e "instinto de nacionalidade" equivalem-se na medida em que funcionam como corretivos a um nacionalismo literário ostensivo ou meramente programático - mas diferenciam-se por completo em sua origem ou significado mais profundo. Se o "instinto de nacionalidade" configura uma busca por inserção em nossa literatura através de um dado que remeta intrinsecamente à sua nacionalidade, o "sentimento íntimo" procurar operar além desse mesmo dado local, inserindo um autor em uma literatura à revelia de qualquer traço extraliterário, externo.

Por ironia, os dois termos têm em si a medida da indefinição: instinto e sentimento, tradicionalmente opostos à reflexão e à razão (e excludentes entre si). Mas não no pensamento crítico de Machado de Assis. Aí, as instâncias de oposição são conformadoras dos termos - instinto é momento inicial da reflexão e também uma sistematização que refreia os excessos da primeira inspiração, já que coloca a obra

\footnotetext{
${ }^{22}$ BAPTISTA, Abel Barros. A formação do nome: duas interrogações sobre Machado de Assis, cit., p. 81.

${ }^{23}$ Idem, p. 109.
} 
literária de uma dada literatura dentro de um projeto nacionalista que seja crítico ao mesmo tempo. O sentimento reivindica para essa mesma literatura a sua literariedade, $\mathrm{o}$ voltar-se para dentro de si de um autor, que se dá ao mesmo tempo no campo do texto literário. Portanto, no universo da crítica literária de Machado de Assis, sentimento e instinto são instâncias críticas, reflexivas, que devem guiar a produção de uma obra literária coerente consigo mesma. Para terminar, lembremos que Machado atesta, em seu ensaio, a existência de um "instinto de nacionalidade" na literatura brasileira contemporânea (1873) - continuidade de uma tradição -; mas almeja a diferenciação que somente pode ser dada pelo "sentimento íntimo" - afirmação da literariedade de uma literatura, seja ela individual ou nacional.

Essa seria a base crítica de juventude sobre a qual irá erguer-se uma das obras romanescas mais consequentes de toda a nossa literatura. Mas essa é uma outra história.

Referências:

ALENCAR, José de. Carta ao Dr. Jaguaribe. In: Ficção completa. v. 2. Rio de Janeiro: Aguilar, 1964.

ASSIS, Machado de. Álvares de Azevedo: Lira dos vinte anos. In: Obra completa. v. 3. Rio de Janeiro: Nova Aguilar, 1997.

José de Alencar: Iracema. In: Obra completa. v. 3. Rio de Janeiro: Nova Aguilar, 1997.

. Notícia da atual literatura brasileira - Instinto de nacionalidade. In:

Obra completa. v. 3. Rio de Janeiro: Nova Aguilar, 1997.

BAPTISTA, Abel Barros. A formação do nome: duas interrogações sobre Machado de Assis. Campinas: Editora da Unicamp, 2003.

SCHWARZ, Roberto. Duas notas sobre Machado de Assis. In: Que horas são? São Paulo: Companhia das Letras, 2006. 
Andréa Sirihal Werkema é professora adjunta de Literatura Brasileira no Instituto de Letras da Universidade do Estado do Rio de Janeiro (UERJ), tendo se doutorado em Literatura Brasileira pelo Programa de Pós-Graduação em Estudos Literários da UFMG. Publicou recentemente: Macário, ou do drama romântico em Álvares de Azevedo (Belo Horizonte: Ed. UFMG, 2012); "Breve comentário acerca do Fragmento A216, de Friedrich Schlegel" (Eutomia: revista de literatura e linguística, ano IV, edição 8, dez. 2011).E-mail: <aswerkema@hotmail.com>

Recebido: $11 / 03 / 2012$

Aprovado: 18/05/2012 